\title{
Front Matter: Volume 10498
}

, "Front Matter: Volume 10498," Proc. SPIE 10498, Multiphoton Microscopy in the Biomedical Sciences XVIII, 1049801 (30 March 2018); doi:

10.1117/12.2323006

SPIE. Event: SPIE BiOS, 2018, San Francisco, California, United States 


\title{
Multiphoton Microscopy in the Biomedical Sciences XVIII
}

\author{
Ammasi Periasamy \\ Peter T. C. So \\ Karsten König \\ Xiaoliang S. Xie \\ Editors
}

\section{8-30 January 2018}

San Francisco, California, United States

Sponsored by

SPIE

Cosponsored by

Becker \& Hickl GmbH (Germany) • Carl Zeiss (United States) • Chroma Technology Corp. (United States) • Coherent Inc. (United States) • Semrock Inc. (United States) • ISS, Inc. (United States) • JenLab GmbH (Germany) • Leica Microsystems (United States) • MKS Instruments (United States) - Applied Scientific Instrumentation (United States) - PicoQuant Photonics (United States)

Published by

SPIE 
The papers in this volume were part of the technical conference cited on the cover and title page. Papers were selected and subject to review by the editors and conference program committee. Some conference presentations may not be available for publication. Additional papers and presentation recordings may be available online in the SPIE Digital Library at SPIEDigitallibrary.org.

The papers reflect the work and thoughts of the authors and are published herein as submitted. The publisher is not responsible for the validity of the information or for any outcomes resulting from reliance thereon.

Please use the following format to cite material from these proceedings:

Author(s), "Title of Paper," in Multiphoton Microscopy in the Biomedical Sciences XVIII, edited by Ammasi Periasamy, Peter T. C. So, Karsten König, Xiaoliang S. Xie, Proceedings of SPIE Vol. 10498 (SPIE, Bellingham, WA, 2018) Seven-digit Article CID Number.

ISSN: 1605-7422

ISSN: $2410-9045$ (electronic)

ISBN: 9781510614819

ISBN: 9781510614826 (electronic)

Published by

SPIE

P.O. Box 10, Bellingham, Washington 98227-0010 USA

Telephone +1 3606763290 (Pacific Time) · Fax +1 3606471445

SPIE.org

Copyright @ 2018, Society of Photo-Optical Instrumentation Engineers.

Copying of material in this book for internal or personal use, or for the internal or personal use of specific clients, beyond the fair use provisions granted by the U.S. Copyright Law is authorized by SPIE subject to payment of copying fees. The Transactional Reporting Service base fee for this volume is $\$ 18.00$ per article (or portion thereof), which should be paid directly to the Copyright Clearance Center (CCC), 222 Rosewood Drive, Danvers, MA 01923. Payment may also be made electronically through CCC Online at copyright.com. Other copying for republication, resale, advertising or promotion, or any form of systematic or multiple reproduction of any material in this book is prohibited except with permission in writing from the publisher. The CCC fee code is 1605 $7422 / 18 / \$ 18.00$.

Printed in the United States of America.

Publication of record for individual papers is online in the SPIE Digital Library.

\section{SPIE. DIGITAL}

Paper Numbering: Proceedings of SPIE follow an e-First publication model. A unique citation identifier (CID) number is assigned to each article at the time of publication. Utilization of CIDs allows articles to be fully citable as soon as they are published online, and connects the same identifier to all online and print versions of the publication. SPIE uses a seven-digit CID article numbering system structured as follows:

- The first five digits correspond to the SPIE volume number.

- The last two digits indicate publication order within the volume using a Base 36 numbering system employing both numerals and letters. These two-number sets start with $00,01,02,03$, 04, 05, 06, 07, 08, 09, OA, OB ... 0Z, followed by 10-1Z, 20-2Z, etc. The CID Number appears on each page of the manuscript. 


\title{
Contents
}

\author{
vii Authors \\ ix Conference Committee \\ xiii Introduction
}

KEYNOTE SESSION

1049804 Metabolic imaging of tumor for diagnosis and response for therapy (Keynote Paper) [10498-3]

\section{METABOLISM/NADH/FAD/TRYPTOPHAN I}

1049806 Ultra-fast HPM detectors improve NAD(P)H FLIM (Invited Paper) [10498-5]

1049807 Multiparametric analysis of cisplatin-induced changes in cancer cells using FLIM (Invited Paper) [10498-6]

\section{METABOLISM/NADH/FAD/TRYPTOPHAN II}

10498 OA Two-photon luminescence lifetime imaging microscopy (LIM) to follow up cell metabolism and oxygen consumption during theranostic applications (Invited Paper) [10498-9]

10498 OB Metabolic imaging for breast cancer detection and treatment: a role for mitochondrial Complex I function (Invited Paper) [10498-10]

10498 OG Multimodal autofluorescence detection of cancer: from single cells to living organism [10498-15]

TECHNOLOGY AND IN VIVO IMAGING I

10498 OK Module for multiphoton high-resolution hyperspectral imaging and spectroscopy [10498-19]

FLIM/FRET/FCS I

$104980 Q$ Measuring upconversion nanoparticles photoluminescence lifetime with FastFLIM and phasor plots (Invited Paper) [10498-25] 
10498 OT Towards monitoring conformational changes of the GPCR neurotensin receptor 1 by singlemolecule FRET (Invited Paper) [10498-28]

10498 OW FastFLIM, the all-in-one engine for measuring photoluminescence lifetime of 100 picoseconds to 100 milliseconds [10498-31]

10498 OX In vivo measurement of astrocytic endfoot $\mathrm{Ca}^{2+}$ and parenchymal vessel responses during 4-AP induced epilepsy using two-photon fluorescence lifetime microscopy [10498-32]

\section{SECOND/THIRD HARMONIC GENERATION}

1049810 Second harmonic generation microscopy of the living human cornea [10498-35]

TECHNOLOGY AND IN VIVO IMAGING II

1049814 Rapid in vivo vertical tissue sectioning by multiphoton tomography [10498-39]

1049816 In vivo three-photon imaging of deep cerebellum [10498-41]

\section{COHERENT RAMAN II}

$1049811 \quad$ Integrated SRS and fluorescence imaging for study of thermogenesis and lipid metabolism in vivo (Invited Paper) [10498-52]

\section{COHERENT RAMAN III}

10498 IP CARS molecular fingerprinting using a sub-nanosecond supercontinuum light source (Invited Paper) [10498-59]

$104981 \mathrm{Q}$ In vivo study of lipid synthesis and lipolysis dynamics by stimulated Raman scattering microscopy [10498-60]

\section{TECHNOLOGY AND IN VIVO IMAGING III}

10498 IV In vivo, two-color multiphoton microscopy using a femtosecond diamond Raman laser [10498-65]

10498 1X Adaptive optics plug-and-play setup for high-resolution microscopes with multi-actuator adaptive lens [10498-67] 
10498 IY 3D brain oxygenation measurements in awake hypertensive mice using two photon phosphorescence lifetime imaging [10498-68]

POSTER SESSION

1049820 Simple fibre based dispersion management for two-photon excited fluorescence imaging through an endoscope [10498-70]

1049822 Rapid and lossless bandwidth-switching of a fiber-based optical parametric oscillator for multimodal nonlinear microscopy [10498-72]

1049823 Electronically tunable femtosecond all-fiber optical parametric oscillator for multi-photon microscopy [10498-73]

1049824 Optimizing Ti:Sapphire laser for quantitative biomedical imaging [10498-74]

1049825 Spatially confined photoinactivation of bacteria: towards novel tools for detailed mechanistic studies [10498-75]

1049827 In vivo multiphoton and fluorescence lifetime imaging microscopy of the healthy and cholestatic liver [10498-77]

1049828 Two-photon activation of endogenous store-operated calcium channels without optogenetics [10498-78]

10498 2A Comparison of excitation wavelengths for in vivo deep imaging of mouse brain (Student Poster Session Competition) [10498-110]

10498 2C Stimulated emission and spontaneous loss pump-probe microscopy for background removal [10498-81]

10498 2D Rapid volumetric multiphoton imaging with the combination of an ultrasound lens and a resonant mirror [10498-82]

$104982 \mathrm{G}$ Enhancement of measurement speed and photon economy in multiphoton detected fluorescence lifetime imaging microscopy [10498-85]

$104982 \mathrm{~J} \quad$ Label-free imaging of acanthamoeba using multimodal nonlinear optical microscopy [10498-87]

$104982 \mathrm{~K} \quad$ Wide field video-rate two-photon imaging by using spinning disk beam scanner [10498-88]

$104982 \mathrm{~L} \quad$ Improvement of two-photon microscopic imaging in deep regions of living mouse brains by utilizing a light source based on an electrically controllable gain-switched laser diode [10498-89]

$104982 \mathrm{M}$ Two-dimensional auto-correlation analysis and Fourier-transform analysis of secondharmonic-generation image for quantitative analysis of collagen fiber in human facial skin [10498-90] 
1049820 Large scale serial two-photon microscopy to investigate local vascular changes in whole rodent brain models of Alzheimer's disease [10498-92]

$104982 \mathrm{U} \quad$ Improving multiphoton STED nanoscopy with separation of photons by Llfetime Tuning (SPLIT) [10498-99]

10498 2W Quantitative 3-dimensional imaging of auxin and cytokinin levels in transgenic soybean and medicago truncatula roots via two-photon induced fluorescence imaging (Student Poster Session Competition) [10498-101]

$104982 Y \quad$ Polymer dots enable deep in vivo multiphoton fluorescence imaging of cerebrovascular architecture [10498-103]

$104982 Z$ Characterization of a reflective objective with multiphoton microscopy [10498-104]

1049830 Improved reference standards for femtosecond three-photon excitation of fluorescence in the wavelength range 950 - $1750 \mathrm{~nm}$ [10498-105]

1049833 Resolution enhancement of 2-photon microscopy using high-refractive index microspheres [10498-108]

1049834 Mueller tensor approach for nonlinear optics in turbid media (Student Poster Session Competition) [10498-109]

1049836 Monitoring agrochemical diffusion through cuticle wax with coherent Raman scattering [10498-113]

1049837 Novel snapshot hyperspectral imager for fluorescence imaging [10498-1 14] 


\section{Authors}

Numbers in the index correspond to the last two digits of the seven-digit citation identifier (CID) article numbering system used in Proceedings of SPIE. The first five digits reflect the volume number. Base 36 numbering is employed for the last two digits and indicates the order of articles within the volume. Numbers start with 00, 01, 02, 03, 04, 05, 06, 07, 08, 09, 0A, OB...0Z, followed by 10-1Z, 20-2Z, etc.

Akiyama, Toshihiro, 1P

Alemán Hérnandez, Felipe Ademir, 24 An, Yitai, 11

Andersen, Peter E., 20

Artal, Pablo, 10

Ávila, Francisco, 10

Baldacchini, Tommaso, OK

Barbieri, Beniamino, OQ, OW

Batista, Ana, 14

Becker, Wolfgang, 06

Bélanger, Samuel, OX

Benda, Aleš, 06

Bijlsma, Hielke, $1 \mathrm{x}$

Bobrov, Nikolai V., 27

Bonora, S., 1X

Börsch, Michael, OT

Breunig, Hans Georg, 14

Breymayer, J., OA

Brinkmann, Maximilian, 22, 23

Bueno, Juan, 10

Cagalinec, M., OG

Capecchi, Mario R., 16

Castello, Marco, $2 \mathrm{U}$

Castonguay, A., 20

Cha, Yu-Rok, 2J

Chandler, Andrea, 37

Chandler, Lynn, 37

Chen, Congping, 1Q

Chen, Shean-Jen, 2D

Cheng, Pan, 28

Chiang, Tsung-Yen, 2D

Chiu, Daniel T., $2 Y$

Chorvat, D., Jr., OG

Choubal, Aakash M., $2 Z$

Coskun, Ulas, $\mathrm{OQ}, \mathrm{OW}$

Coto Hernández, Iván, $2 U$

Couderc, Vincent, 1P, 2J

Cunderlikova, B., OG

Damseh, R., 20

Darafsheh, Arash, 33

Das, Subir, 2C

Delafontaine-Martel, P., 20

Deng, Fengyuan, 34

Diaspro, Alberto, $2 \mathrm{U}$

Dimopoulos, Konstantinos, 20

Ding, Changqin, 34

Dudenkova, Varvara V., 04, 07, 27

Dunn, Andrew K., 1V, $2 Y$

Elagin, Vadim, 04
Enger, Jonas, 24

Ericson, Marica B., 24, 25

Fallnich, Carsten, 22, 23

Fang, Yi-Cheng, $2 \mathrm{~L}$

Farewell, Anne, 25

Fellbaum, Carl, 2W

Fisher, Jon, 2W

Gaillard, Paul, 2W

Gaunt, Nicholas P., 36

Gavrina, Alena I., 07

Girouard, Hélène, OX

Grisshammer, Reinhard, OT

Guru, Akash, 16

Hanstorp, Dag, 24

Hase, Eiji, $2 M$

Hassan, Ahmed M., 1V, 2Y

$\mathrm{He}, \mathrm{HaO}, 28$

$\mathrm{He}$, Sicong, $11,1 \mathrm{Q}$

Heitkamp, Thomas, OT

Hellwig, Tim, 22, 23

Ho, Bo-Wei, 2C

Horilova, J., OG

Hsu, Chia-Wei, 2D

Hung, Jui-Hung, $2 \mathrm{~L}$

Hwang, Wonsang, $2 \mathrm{G}$

Ignatova, Nadezgda, 04

Inoko, Akihito, 1P

Ito, Yoko, 2K

James, Jeemol, 24, 25

Jarrett, Jeremy W., 1V, 2 Y

Jowett, Nate, $2 \mathrm{U}$

Kabir, Mohammad M., $2 Z$

Kaji, Yuichi, 1P, 2J

Kalinina, S., OA

Kano, Hideaki, 1P, 2J

Kao, Fu-Jen, 2C

Kawakami, Ryosuke, 2L

Kim, Dongeun, 2G

Kim, Dug Young, 2G

Kobayashi, Tsubasa, 1P, 2J

König, Karsten, 14

Kozawa, Yuichi, 2L

Kurokawa, Kazuo, 2K

Kuznetsova, Daria S., 27

Lai, Feng-Jie, 2D

Lanzano, Luca, 2U

Lee, Hsien-Ming, $0 Q$

Lefebvre, J., 20

Leproux, Philippe, 1P, 2J 
Lesage, Frédéric, $0 X, 1 Y, 20$

$\mathrm{Li}$, Baoqiang, $1 \mathrm{Y}$

Li, Bo, 16, 2A

Li, Xuesong, 1I, 1Q

Li, Yan, $1 Q$

Liao, Shih-Chu Jeff, OQ, OW

Lilge, L., OA

Liu, Yen-Liang, $2 Y$

Lu, Xuecong, OX, $1 Y$

Lukina, Maria, 04

Lukyanov, Konstantin A., 07

Maeda, Yasuhiro, 2K

Mak, Ho Yi, 1Q

Mandel, A., OA

Marcek Chorvatova, A., OG

Marti, Dominik, 20

Mikhaylov, Alexander, 30

Miller, David R., 1V, 2Y

Moeini, Mohammad, $0 X, 1 Y$

Moger, Julian, 36

Moon, Sucbei, $2 \mathrm{G}$

Mortensen, Luke J., 33

Nakano, Akihiko, 2K

Nam, Hyung-Song, 16

Nemoto, Tomomi, 2L

Nurmalasari, Ni Putu Dewi, 2W

Ogura, Yuki, 2M

Orlinskay, Natalia, 04

Oshika, Tetsuro, 1P, 2J

Otomo, Kohei, $2 \mathrm{~L}$

Ouzounov, Dimitre G., 16

Padia, Faheem, 36

Periasamy, Ammasi, 37

Perillo, Evan P., 1V, 2 Y

Phang, Sendy, 33

Pozzi, P., $1 \mathrm{X}$

Qin, Zhongya, 1Q

Qiu, Hailin, $O Q$

QU, Jianan Y., 11, 1Q

Quintavalla, M., 1X

Ramanujan, $\mathrm{V}$. Krishnan, $\mathrm{OB}$

Rebane, Aleksander, 30

Rodimova, Svetlana A., 27

Rothe, Sebastian, 24

Rück, A., OA

Sakadžić, Sava, 1 Y

Sato, Shunichi, $2 \mathrm{~L}$

Sawada, Kazuaki, 2 L

Schäfer, P., OA

Scheslavsky, Vladislav, 04

Sergeeva, Tatiana F., 07

Shirmanova, Marina $\vee ., 04,07$

Shlivko, Irena, 04

Simpson, Garth J., 34

Sinefeld, David, 16, 2A

Sivaguru, Mayandi, $2 Z$

Smith, Steve, 2W

Studier, Hauke, 06

Subramaniam, Sen, 2W

Sun, Yuansheng, OQ, OW
Tabatabaei, Maryam, OX

Tanaka, Yuji, 2M

Tang, Wanyi, 28

Tardif, P., 20

Tehrani, Kayvan Forouhesh, 33

Thomsen, Hanna, 24, 25

Thomson, Niall, 36

Tortarolo, Giorgio, $2 \mathrm{U}$

Toussaint, Kimani C., Jr., $2 Z$

Ulcickas, James R. W., 34

Verhaegen, Michelle, $1 \mathrm{X}$

Verstraete, Hans, $1 \mathrm{X}$

Vicidomini, Giuseppe, $2 U$

von Arnim, C., OA

von Einem, B., OA

Wada, Satoshi, 2K

Wang, Mengran, 16, 2A

Wang, Tianyu, 16

Warden, Melissa R., 16

Wetzker, Cornelia, 06

Won, Youngjae, 2G

Wu, Chunyan, 16, 2A

$\mathrm{Wu}, \mathrm{XU}, 2 \mathrm{Y}$

Wu, Zhenguo, 11

Xia, Fei, 2A

$\mathrm{Xu}$, Chris, 16, 2A

$X U$, Shihan, $2 Y$

Yamashita, Toyonobu, 2M

Yasui, Takeshi, 2M

Yeh, Hsin-Chih, $2 Y$

Yokoyama, Hiroyuki, 2L

Yu, Jiangbo, $2 Y$

Zadoyan, Ruben, OK

Zagainov, Vladimir E., 27

Zagaynova, Elena V., 04, 07, 27

Zeytunyan, Aram, OK

Zhang, Cong, $O X, 1 Y$ 


\title{
Conference Committee
}

\author{
Symposium Chairs
}

James G. Fujimoto, Massachusetts Institute of Technology

(United States)

R. Rox Anderson, Wellman Center for Photomedicine, Massachusetts

General Hospital (United States) and Harvard Medical School

(United States)

Program Track Chairs

Ammasi Periasamy, University of Virginia (United States)

Daniel L. Farkas, University of Southern California (United States) and SMI (United States)

Conference Chairs

Ammasi Periasamy, University of Virginia (United States)

Peter T. C. So, Massachusetts Institute of Technology (United States)

Karsten König, Universität des Saarlandes (Germany)

Xiaoliang S. Xie, Harvard University (United States) and Peking University (China)

Conference Program Committee

Holly Aaron, University of California, Berkeley (United States)

Margarida Barroso, Albany Medical College (United States)

Wolfgang Becker, Becker \& Hickl GmbH (Germany)

Alberto Diaspro, Istituto Italiano di Tecnologia (Italy)

Chen-Yuan Dong, National Taiwan University (Taiwan)

Paul J. Campagnola, University of Wisconsin-Madison (United States)

Ji-Xin Cheng, Purdue University (United States)

Kevin W. Eliceiri, University of Wisconsin-Madison (United States)

Scott Fraser, University of Southern California (United States)

Paul M. W. French, Imperial College London (United Kingdom)

Katsumasa Fujita, Osaka University (Japan)

Enrico Gratton, University of California, Irvine (United States)

Min Gu, RMIT University (Australia)

Stefan W. Hell, Max-Planck-Institut für Biophysikalische Chemie (Germany)

Fu-Jen Kao, National Yang-Ming University (Taiwan)

Arnd K. Krueger, Spectra-Physics (United States) 
Joseph R. Lakowicz, University of Maryland School of Medicine (United States)

Steve M. McDonald, Coherent, Inc. (United States)

Wei Min, Columbia University (United States)

Junle Qu, Shenzhen University (China)

Angelika C. Rueck, Universität Ulm (Germany)

Yuansheng Sun, ISS, Inc. (United States)

Steven S. Vogel, National Institutes of Health (United States)

Chris Xu, Cornell University (United States)

Elena V. Zagaynova, Nizhny Novgorod State Medical Academy (Russian Federation)

Bernhard Zimmermann, Carl Zeiss Jena GmbH (Germany)

\section{Session Chairs}

1 Keynote Session

Ammasi Periasamy, University of Virginia (United States)

2 Metabolism/NADH/FAD/Tryptophan I

Angelika C. Rueck, Universität Ulm (Germany)

3 Metabolism/NADH/FAD/Tryptophan II

Elena V. Zagaynova, Nizhny Novgorod State Medical Academy (Russian Federation)

Marina V. Shirmanova, Nizhny Novgorod State Medical Academy (Russian Federation)

4 Technology and In Vivo Imaging I

Peter T. C. So, Massachusetts Institute of Technology (United States)

5 FLIM/FRET/FCS I

Kevin W. Eliceiri, University of Wisconsin-Madison (United States)

6 FLIM/FRET/FCS II

Yuansheng Sun, ISS, Inc. (United States)

Margarida Barroso, Albany Medical College (United States)

7 Second/Third Harmonic Generation

Paul J. Campagnola, University of Wisconsin-Madison (United States)

8 Technology and In Vivo Imaging II

Fu-Jen Kao, National Yang-Ming University (Taiwan)

9 Coherent Raman I

Ji-Xin Cheng, Purdue University (United States) 
10 Coherent Raman II

Wei Min, Columbia University (United States)

11 Coherent Raman III

Lingyan Shi, Columbia University (United States)

12 Technology and In Vivo Imaging III

Ammasi Periasamy, University of Virginia (United States)

Proc. of SPIE Vol. 10498 1049801-11

Downloaded From: https://www.spiedigitallibrary.org/conference-proceedings-of-spie on 25 Apr 2023 Terms of Use: https://www.spiedigitallibrary.org/terms-of-use 
Proc. of SPIE Vol. 10498 1049801-12 Downloaded From: https://www.spiedigitallibrary.org/conference-proceedings-of-spie on 25 Apr 2023
Terms of Use: https://www.spiedigitallibrary.org/terms-of-use 


\section{Introduction}

Multiphoton microscopy has been established as the 3-D imaging method of choice for studying biomedical specimens from single cells and whole animals to patients with submicron resolution. 27 years have passed since the realization of two-photon laser scanning microscopy. The ever-expanding scope of applications and the continuing instrumental innovations requires a forum where new ideas can be exchanged and presented. Our conference at the SPIE BIOS 2018 meeting continues to address this need.

This is the $18^{\text {th }}$ year of this conference and we start our conference with four Keynote lectures from leaders in the field of Metabolism:

Dr. Wei Min, Columbia University, NY, USA, "Seeing molecular vibrations: Chemical imaging for biomedicine."

Dr. Enrico Gratton, University of California at Irvine, CA, USA, "Spectroscopic signatures of cells metabolism and extracellular species using phasor-FLIM."

Dr. Elena V. Zagaynova, Nizhny Novgorod State Medical Academy, Nizhny Novgorod, Russian Federation, "Metabolic imaging of tumor for diagnosis and response for therapy."

Dr. Lihong V. Wang, California Institute of Technology, CA, USA, "Photoacoustic tomography: Ultrasonically beating optical diffusion for deep imaging."

For 18 years in a row, the conference organized poster awards for the students and postdoctoral fellows. The poster award was donated by all the conference sponsors as acknowledged at the bottom of the page.

The 2 poster award winners are

1. James R. W. Ulcickas, Purdue University, USA, "Mueller tensor approach for nonlinear optics in turbid media." Paper 10498-109.

2. Mengran Wang, Cornell University, USA, "Comparison of excitation wavelengths for in vivo deep imaging of mouse brain." Paper 10498-110.

Some of the most valuable contributions in this volume are articles written by highly experienced practitioners of multiphoton microscopy. They have enumerated the most important considerations in designing multiphoton microscopes and imaging experiments. Further, updates on the state-of-the-art commercial multiphoton microscope systems are presented. This volume also includes articles describing some recent advances in major multiphoton microscope components and applications including laser light sources, ultrafast optics, filters, FRET, FLIM, FCS, Raman, CARS, SRS and Coherent Raman microscopy and spectroscopy, single molecule, endoscopy, In Vivo/Intravital imaging, metabolism measurements including NADH, FAD, tryptophan in cells and tissues and various scientific and clinical applications. 
On a personal note, the conference chairs are grateful for the participation of all authors and session chairs. We acknowledge the innovation-driven manufacturers and sponsors of this conference [Applied Scientific Instrumentation, Becker \& Hickl GmbH, Carl Zeiss, Chroma Technology Corp., Coherent Inc., ISS Inc., JenLab GmbH, Leica Microsystems, PicoQuant Photonics, Semrock Inc., and Spectra Physics \& Newport (An MKS Company)] for their enthusiastic support in organizing this conference successfully for the last 18 years. We look forward to other exciting conferences in the future and welcome your continued participation and support.

\section{Ammasi Periasamy Peter T. C. So \\ Karsten König Xiaoliang S. Xie}

